\title{
Obtaining Ultra-High Strength and Ductility in a Mg-Gd-Er-Zn-Zr Alloy via Extrusion, Pre-deformation and Two-Stage Aging
}

\author{
Lin-Yue Jia ${ }^{1}$. Wen-Bo Du ${ }^{1}$. Jin-Long Fu ${ }^{1}$ Zhao-Hui Wang ${ }^{1} \cdot \mathrm{Ke} \mathrm{Liu}^{1} \cdot$ Shu-Bo Li ${ }^{1} \cdot$ Xian $\mathrm{Du}^{1}$
}

Received: 30 March 2020 / Revised: 2 July 2020 / Accepted: 3 July 2020 / Published online: 5 September 2020

(c) The Chinese Society for Metals (CSM) and Springer-Verlag GmbH Germany, part of Springer Nature 2020

\begin{abstract}
The $\mathrm{Mg}-12 \mathrm{Gd}-1 \mathrm{Er}-1 \mathrm{Zn}-0.9 \mathrm{Zr}$ (wt $\%$ ) alloy with ultra-high strength and ductility was developed via hot extrusion combined with pre-deformation and two-stage aging treatment. The age-hardening behavior and microstructure evolution were investigated. Pre-deformation introduced a large number of dislocations, resulting in strain hardening and higher precipitation strengthening in the subsequent two-stage aging. As a result, the alloy showed a superior strength-ductility balance with a yield strength of $506 \mathrm{MPa}$, an ultimate tensile strength of $549 \mathrm{MPa}$ and an elongation of $8.2 \%$ at room temperature. The finer and denser $\beta^{\prime}$ precipitates significantly enhanced the strength, and the bimodal structure, small $\beta-\mathrm{Mg}_{5} \mathrm{RE}$ phase as well as dense $\gamma^{\prime}$ precipitates ensured the good ductility of the alloy. It is suggested that the combination of pre-deformation and two-stage aging treatment is an effective method to further improve the mechanical properties of wrought $\mathrm{Mg}$ alloys.
\end{abstract}

Keywords Magnesium alloys $\cdot$ Pre-deformation $\cdot$ Two-stage aging $\cdot$ Precipitation strengthening $\cdot$ Mechanical properties

\section{Introduction}

Due to the great potential for weight reduction in aerospace and automotive industries, $\mathrm{Mg}-\mathrm{RE}(-\mathrm{Zn})$ (RE: rare earth) alloys with outstanding mechanical performance have been widely investigated for decades. Heavy RE elements such as $\mathrm{Gd}$ and $\mathrm{Y}$ are frequently selected as the main alloying elements, because they usually have high solid solubility in $\mathrm{Mg}$ matrix at elevated temperatures. In particular, Gd addition significantly enhances the age-hardening response due to the sharp decline in equilibrium solid solubility of $\mathrm{Gd}$ in $\mathrm{Mg}$ with decrease in temperature (from $23.5 \mathrm{wt} \%$ at $548{ }^{\circ} \mathrm{C}$ to only $3.8 \mathrm{wt} \%$ at $200{ }^{\circ} \mathrm{C}$ ) [1-3]. The main strengthening phase formed in $\mathrm{Mg}-\mathrm{Gd}$ based alloys during aging treatment is prismatic $\beta^{\prime}$ precipitates with a base centered orthorhombic (bco) structure. A series of high-strength $\mathrm{Mg}-\mathrm{Gd}(-\mathrm{Zn}$ ) based alloys have been successfully fabricated by deformation processing such as extrusion [3, 4] and rolling [5, 6]. For example, the $\mathrm{Mg}-8 \mathrm{Gd}-1 \mathrm{Er}-0.5 \mathrm{Zr}$ (wt\%) alloy [5] and

Available online at http://link.springer.com/journal/40195.

Wen-Bo Du

duwb@bjut.edu.cn

1 College of Materials Science and Engineering, Beijing University of Technology, Beijing 100124, China
Mg-11.7Gd-4.5Y-1Nd-1.5Zn-0.5Zr (wt\%) alloy [6] developed through extrusion, rolling and aging both have over $500 \mathrm{MPa}$ yield strength. However, magnesium alloys are still restricted in engineering applications because of their lower yield strength (YS) and ductility, and hence, there are large spaces and challenges in achieving Mg alloys with ultra-high strength and ductility [7]. Besides alloy design, an effective processing method is also important to realize synchronous improvement in strength and ductility.

For precipitation hardened alloys, the size and distribution of precipitates are crucial for strengthening [7, 8]. The control of precipitation can be obtained by increasing nucleation rate and optimizing aging treatment. Introducing lattice defects has been noted to facilitate heterogeneous nucleation and enhance age-hardening response [9, $10]$. A high-strength $\mathrm{Mg}-14 \mathrm{Gd}-0.5 \mathrm{Zr}$ (wt\%) alloy was prepared by extrusion, cold rolling and aging, showing a YS of $445 \mathrm{MPa}$, an ultimate tensile strength (UTS) of $482 \mathrm{MPa}$ and an elongation (EL) of $2.0 \%$ [10]. For the peak-aged alloys, pre-deformation such as cold rolling or tensile/compress deformation improves precipitation strengthening but causes severe loss of ductility at the same time. It is also reported that a rapid annealing out of dislocations at the beginning of aging would greatly reduce the strengthening effect of pre-deformation, and little further improvement in strength is expected for tensile deformation with larger strain [9]. 
As we known, aging plays a major role in precipitation behavior and the enhancement of mechanical properties of alloys, but the optimum mechanical performance cannot always be obtained through single aging treatment. Crawley et al. [11] compared the precipitation structures of single and two-stage aged AZ91 alloy, and concluded that the orientation of precipitates was not altered by two-stage aging, and the increase in strength could be attributed to the decrease in inter-precipitate spacing by pre-aging treatment, which provided more nucleation sites for the subsequent precipitation. Oh-ishi et al. [12] studied the transformation mechanism of precipitates in $\mathrm{Mg}-\mathrm{Zn}$ alloys during the multistage aging process, and reported that the distribution and morphology of precipitates were significantly changed compared with single aging, which resulted in the improvement in mechanical properties. Zhang et al. [13] reported that two-stage aging treatment on $\mathrm{Mg}-8 \mathrm{Gd}-4 \mathrm{Y}-\mathrm{Nd}-\mathrm{Zr}$ alloy improved both strength and ductility. Therefore, it is considered that two-stage aging may be more favorable to obtaining high performance of $\mathrm{Mg}$ alloys than conventional single aging treatment.

In this work, the $\mathrm{Mg}-12 \mathrm{Gd}-1 \mathrm{Er}-1 \mathrm{Zn}-0.9 \mathrm{Zr}$ (wt\%) alloy with ultra-high strength and ductility was obtained by extrusion combined with pre-deformation and two-stage aging, exhibiting YS of $506 \mathrm{MPa}$, UTS of $549 \mathrm{MPa}$ and EL of $8.2 \%$. The microstructure evolution and aging behavior were evaluated, and the corresponding mechanisms were discussed.

\section{Experimental}

The Mg-12Gd-1Er-1Zn-0.9Zr (wt\%) alloy was prepared from pure $\mathrm{Mg}$, pure $\mathrm{Zn}, \mathrm{Mg}-30 \mathrm{Gd}$ (wt\%), Mg-30Er (wt\%) and $\mathrm{Mg}-12 \mathrm{Zr}$ (wt\%) master alloys via conventional casting. The ingot was melted in an electric resistance furnace under the protection of mixed $\mathrm{SF}_{6}(5 \mathrm{vol} \%)+\mathrm{N}_{2}(95 \mathrm{vol} \%)$ gas. The melt was poured into a steel mold and then cooled down in water. The actual chemical composition of the cast alloy was measured by X-ray fluorescence analyzer (XRF, Magic PW2403), which was Mg-12.39Gd-1.05Er-1.13Zn-0.88Zr (wt\%). Solution treatment was performed at $520^{\circ} \mathrm{C}$ for $12 \mathrm{~h}$ and then immediately quenched into warm water. Indirect extrusion was conducted at $\sim 405^{\circ} \mathrm{C}$ under an extrusion ratio of 10 , followed by quenching in water at room temperature. Some extruded rods were then subjected to pre-deformation with a plastic strain of $\sim 4 \%$ using a universal testing machine. Tensile deformation was conducted parallel to the extrusion direction (ED) at room temperature with a strain rate of $1 \times 10^{-4} \mathrm{~s}^{-1}$. The extruded rods without/with predeformation were denoted as E and EPD samples, respectively. Subsequently, two-stage aging (TSA) was carried out by pre-aging at $100{ }^{\circ} \mathrm{C}$ for $1 \mathrm{~h}$ (stage I), followed by aging at
$200{ }^{\circ} \mathrm{C}$ (stage II). The peak-aged samples were denoted as $\mathrm{E}+\mathrm{TSA}$ and EPD + TSA.

Microstructures were observed using electron backscatter diffraction (EBSD) and transmission electron microscope (TEM, JEOL JEM-2100FX). EBSD was conducted on a scanning electron microscope (SEM, FEI QUANTA FEG 650) equipped with an HKL-EBSD system. The macro-texture of samples was measured by X-ray diffraction (XRD, BRUKER D8 DISCOVER). The hardness was measured under a load of $100 \mathrm{~g}$ and holding time of $10 \mathrm{~s}$ by Vickers hardness testing. Dog-bone shaped specimens (gauge dimensions: $\Phi 5 \mathrm{~mm} \times 25 \mathrm{~mm}$ ) were machined for tensile testing on a DNS-20 universal test machine with a strain rate of $5 \times 10^{-4} \mathrm{~s}^{-1}$ at room temperature. The tensile direction was parallel to the ED.

\section{Results and discussion}

Figure 1a shows the age-hardening behavior of the E and EPD samples. It can be observed that the hardness of the two samples showed little change during pre-aging (stage I), but both samples exhibited significant hardening response at age temperature of $200{ }^{\circ} \mathrm{C}$ (stage II). The hardness of the $\mathrm{E}$ and EPD samples was $92 \mathrm{HV}$ and $95 \mathrm{HV}$, respectively, and the peak-hardness showed $116 \mathrm{HV}$ for the E+TSA sample and $118 \mathrm{HV}$ for the EPD + TSA sample after aging at $100{ }^{\circ} \mathrm{C}$ for $1 \mathrm{~h}$ plus $200{ }^{\circ} \mathrm{C}$ for $40 \mathrm{~h}$. This indicates that the hardness of the alloy increased due to strain hardening after pre-deformation treatment, and the peak-hardness value increased during the subsequent aging. Note that the EPD sample had a higher hardening rate than the E sample between 4 and $20 \mathrm{~h}$ of stage II, which is associated with the dislocations introduced by pre-deformation. Dislocations can act as nucleation sites for precipitates and rapid diffusion channels for solute atoms, enhancing the aging behavior of the alloy [2, 14]. However, the time for both samples to reach peak-aging was the same. This might be associated with the fact that the more nucleation sites and faster growth rate for precipitates in the EPD + TSA sample consumed more RE elements during the early period of aging, resulting in a reduction in precipitation driving force and lower hardening rate in the subsequent aging, accordingly the shortening of peak time caused by the tensile deformation was not obvious in the alloys with higher RE content. Such phenomenon was consistent with the previous study [15].

The stress-strain tensile curves of the E, EPD, E+TSA and EPD+ TSA samples are shown in Fig. 1b. The YS, UTS and EL of the E sample were $358 \mathrm{MPa}, 406 \mathrm{MPa}$ and $10.5 \%$, respectively. After $4 \%$ pre-deformation, the YS and UTS were improved, especially the YS increased to $403 \mathrm{MPa}$. This is mainly attributed to the strain hardening effect, which deteriorated the ductility of the alloy. The E+TSA sample 
(a)

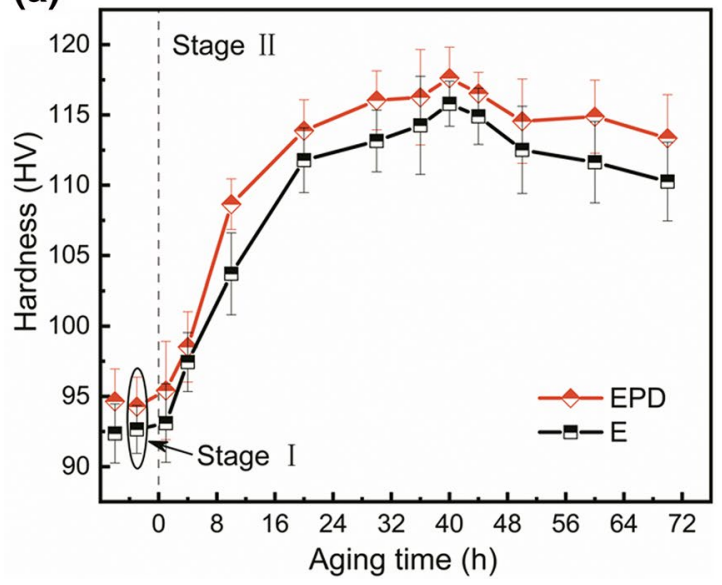

(b)

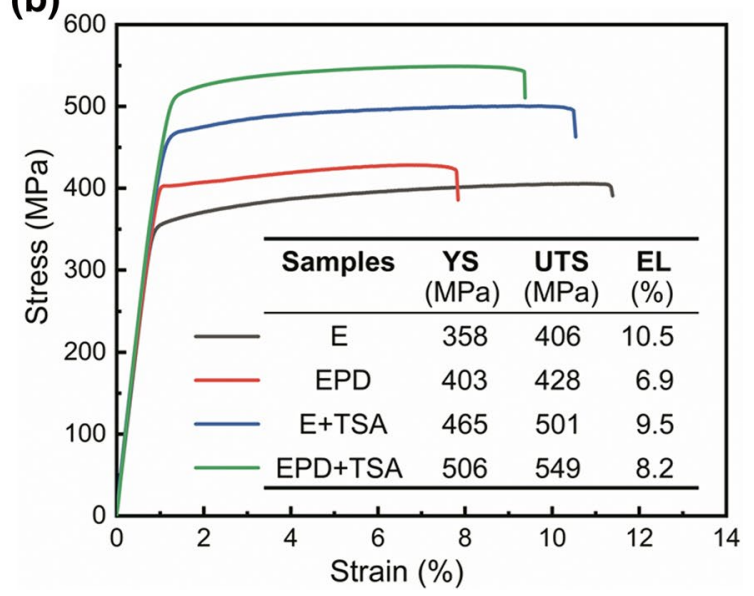

Fig. 1 a Age-hardening behavior of the E and EPD samples, $\mathbf{b}$ tensile engineering stress-strain curves of the various samples

showed the YS of $465 \mathrm{MPa}$, UTS of $501 \mathrm{MPa}$ and EL of $9.5 \%$. It is noteworthy that the two-stage aging treatment further enhanced the strength without drastic reduction in ductility. Moreover, the EPD+TSA sample exhibited ultra-high YS of $506 \mathrm{MPa}$, UTS of $549 \mathrm{MPa}$ and EL of 8.2\%, showing superior strength-ductility balance than the other wrought $\mathrm{Mg}-\mathrm{RE}$ alloys previously reported [3, 15, 16]. Confined to our knowledge, the Mg-12.6Gd-1.3Y-0.9Zn-0.5Mn (wt\%) alloy processed via extrusion, cold rolling, cold stretching and aging, exhibited the highest reported YS (543 MPa) of $\mathrm{Mg}$ alloys by ingot metallurgy (IM), while its elongation was only $1.2 \%$ [15]. Apparently, the EPD+ TSA alloy with superior strength-ductility balance prepared by a simpler process in this study is more promising for engineering application. In addition, the present alloy shows more excellent mechanical properties with lower RE content compared with the T5-treated Mg-15Gd-1Zn-0.4Zr (wt\%) alloy, which has a YS of $465 \mathrm{MPa}$, an UTS of $524 \mathrm{MPa}$ and an EL of $4.0 \%$ [3]. The combination of pre-deformation and two-stage aging provides an effective way to achieve high-performance $\mathrm{Mg}$ alloys.

Figure 2a, $d$ show the EBSD inverse pole figure (IPF) maps of the E + TSA and EPD + TSA samples viewed along the ND. It is evident that the alloy comprised fine dynamically recrystallized (DRXed) grains and coarse worked grains with large aspect ratio, showing a typical bimodal structure after extrusion. The average DRXed grain size of both E + TSA and EPD + TSA samples was $\sim 1.4 \mu \mathrm{m}$, and few twins were observed. It reveals that the bimodal microstructure was almost unchanged during the pre-deformation process, and dislocation slip was the main deformation mode. The line profiles of the misorientation angle along the black arrows in the IPF maps are shown in Fig. 2b, e. As can be seen, the accumulated misorientation of worked grains in the EPD + TSA sample was much higher than that in the E+TSA sample. The point-to-origin misorientation increased continuously from $0^{\circ}$ to $22^{\circ}$ within $60 \mu \mathrm{m}$ (Fig. 2e), indicating that a large misorientation gradient occurred inside the grains due to the high-density dislocations introduced by pre-deformation [17]. Figure $2 \mathrm{c}$, f show the macro-texture of the E+TSA and EPD+TSA samples on the ED-TD plane tested by XRD. Obviously, both samples presented a typical extrusion basal texture with (0002) basal planes parallel to the ED and had similar maximum intensity. As a result, the pre-deformation with small strain had little effect on the microstructure and macro-texture of the alloy.

Figure 3a shows the bright-field (BF) image obtained from DRXed grains of the EPD sample. A large number of dislocations (marked by red arrows) within grains were observed. In addition to the dislocations generated during the extrusion process, pre-deformation along the ED introduced more dislocations including non-basal $\langle c+a\rangle$ dislocations [18], resulting in strain hardening effect. Compared with E sample, a higher dislocation density was expected in the EPD sample. The stage I aging at lower temperature weakened the recovery of dislocations, which combined with the higher supersaturation of solute atoms to increase the number of nucleation sites [19]. Figure 3b-d show the TEM micrographs and corresponding selected area electron diffraction (SAED) patterns obtained from the interior of DRXed grains of peak-aged samples along $[0001]_{\alpha-\mathrm{Mg}}$. Dense $\beta^{\prime}$ precipitates with bco structure $[20,21]$ formed during the peak-aging treatment. As shown in Fig. 3b, d, the average diameter of the $\beta^{\prime}$ precipitates were about $10 \mathrm{~nm}$ for the E+TSA sample and $8 \mathrm{~nm}$ for the EPD + TSA sample, and denser $\beta^{\prime}$ precipitates were obtained in the EPD + TSA sample. The strengthening effect of the prismatic $\beta^{\prime}$ precipitates was enhanced after pre-deformation. Meanwhile, the intermediate structures [22] (marked by white arrows 

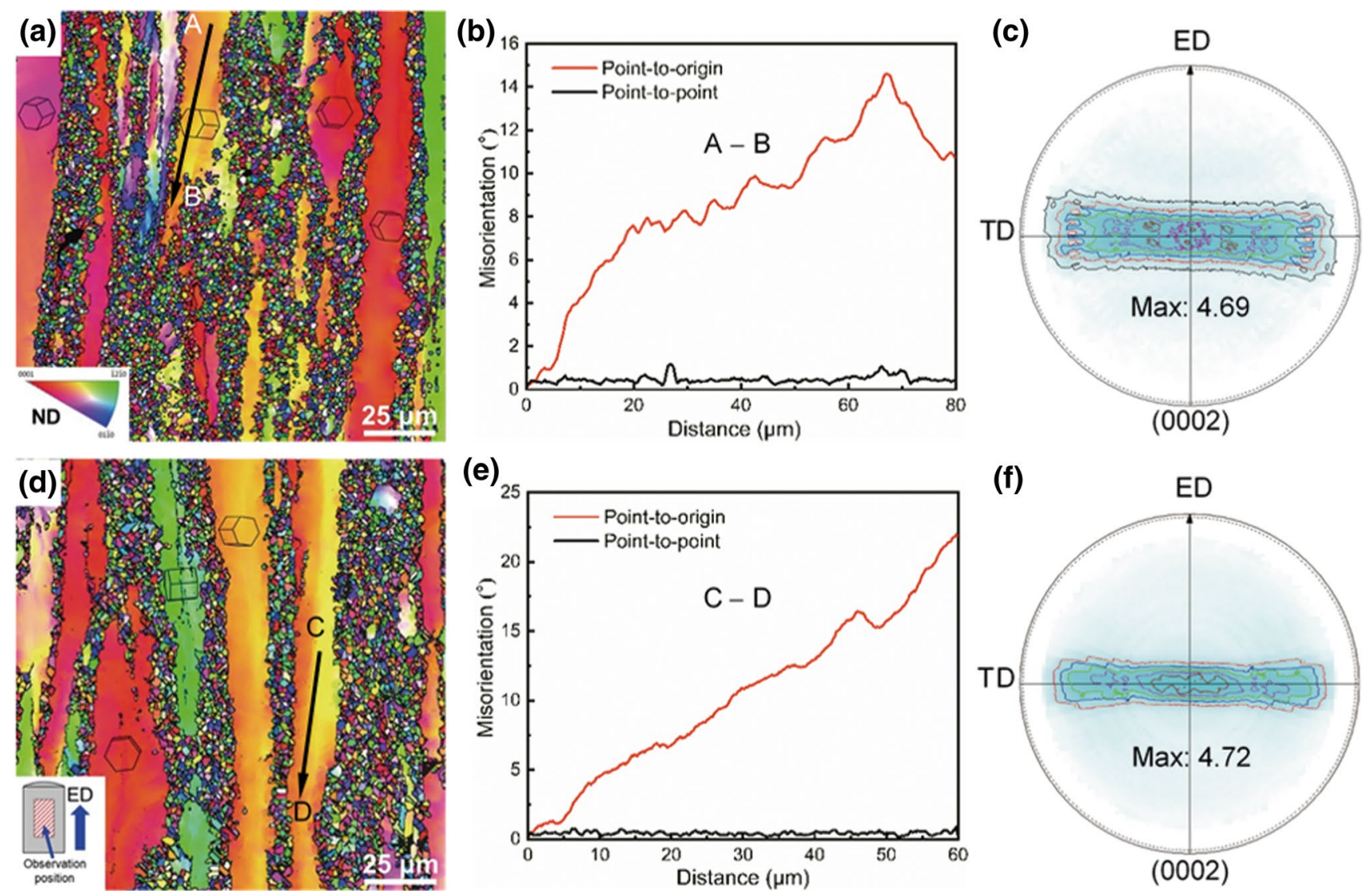

Fig. 2 EBSD results and corresponding pole figures (tested by XRD) of a-c E + TSA, $\mathbf{d}-\mathbf{f}$ EPD + TSA samples: a, $\mathbf{d}$ IPF maps, $\mathbf{b}, \mathbf{e}$ line profiles of the misorientation angle along the black arrow in $\mathbf{a}, \mathbf{d}, \mathbf{c}, \mathbf{f}(0002)$ pole figures

in Fig. 3b, d) were also observed, and its number density seemed to be higher in the EPD + TSA sample. The increased precipitation of the intermediate structures might be attributed to the higher dislocation density induced by pre-deformation, and contributed to the strength together with the $\beta^{\prime}$ and basal $\gamma^{\prime}$ precipitates [15]. In addition, an interesting phenomenon was noted from the low magnification morphology, as given in Fig. 3c. Dense precipitates distributed along the lines of dark contrast, which were previously dislocations like as shown in Fig. 3a. The enlarged image of the region marked by the white dashed box (the bottom inset in Fig. 3c) indicates that the $\beta^{\prime}$ precipitates preferentially formed at the heterogeneous nucleation sites provided by dislocations and grew rapidly, accompanied with intermediate structures. This is associated with the high dislocation density, which is proportional to the nucleation rate on dislocation lines, and the increase in solute concentration near dislocations caused by the stress field. This interaction between solute atoms and dislocations, i.e., line strengthening, a kind of pipe diffusion process [23], is considered to lead the higher hardening rate of the EPD + TSA sample in the early aging (see Fig. 1a). The precipitates in the coarse worked grains presented similar distribution to the DRXed grains [24], and only the number density of the precipitates in the worked grains might be slightly higher due to the accumulation of more dislocations. As the main precipitates in the aging process, the finer and denser $\beta^{\prime}$ precipitates contributed to the strength improvement in the EPD + TSA sample.

To reveal the toughening mechanism, further TEM observations were performed on the EPD + TSA sample. Figure 4a shows the TEM BF image of the DRXed region. Numerous $\beta-\mathrm{Mg}_{5} \mathrm{RE}$ [5] phase with an average size of $\sim 130 \mathrm{~nm}$ precipitated at the DRXed grain boundaries and in the matrix. These relatively small $\beta$ phase benefited the deformation compatibility at the DRXed grain boundaries, without deteriorating the ductility like coarse $\beta$ particles, such as the $\beta$ particles with an average size of $347 \mathrm{~nm}$ in the $\mathrm{Mg}-1.8 \mathrm{Gd}-1.8 \mathrm{Y}-0.7 \mathrm{Zn}-0.2 \mathrm{Zr}$ (at\%) alloy $[4,25]$. Thus, the small $\beta-\mathrm{Mg}_{5} \mathrm{RE}$ phase and fine DRXed grains formed during extrusion strengthened the alloy and contributed to the good ductility. The HAADF-STEM micrograph and corresponding SAED pattern taken from the precipitates inside worked grains along $[11 \overline{2} 0]_{\alpha-M g}$ are shown in Fig. 4b. Dense basal $\gamma^{\prime}$ precipitates distributing parallel to $(0002)_{\alpha-M g}$ co-existed with the $\beta^{\prime}$ precipitates in the peak-aged sample. The $\gamma^{\prime}$ 

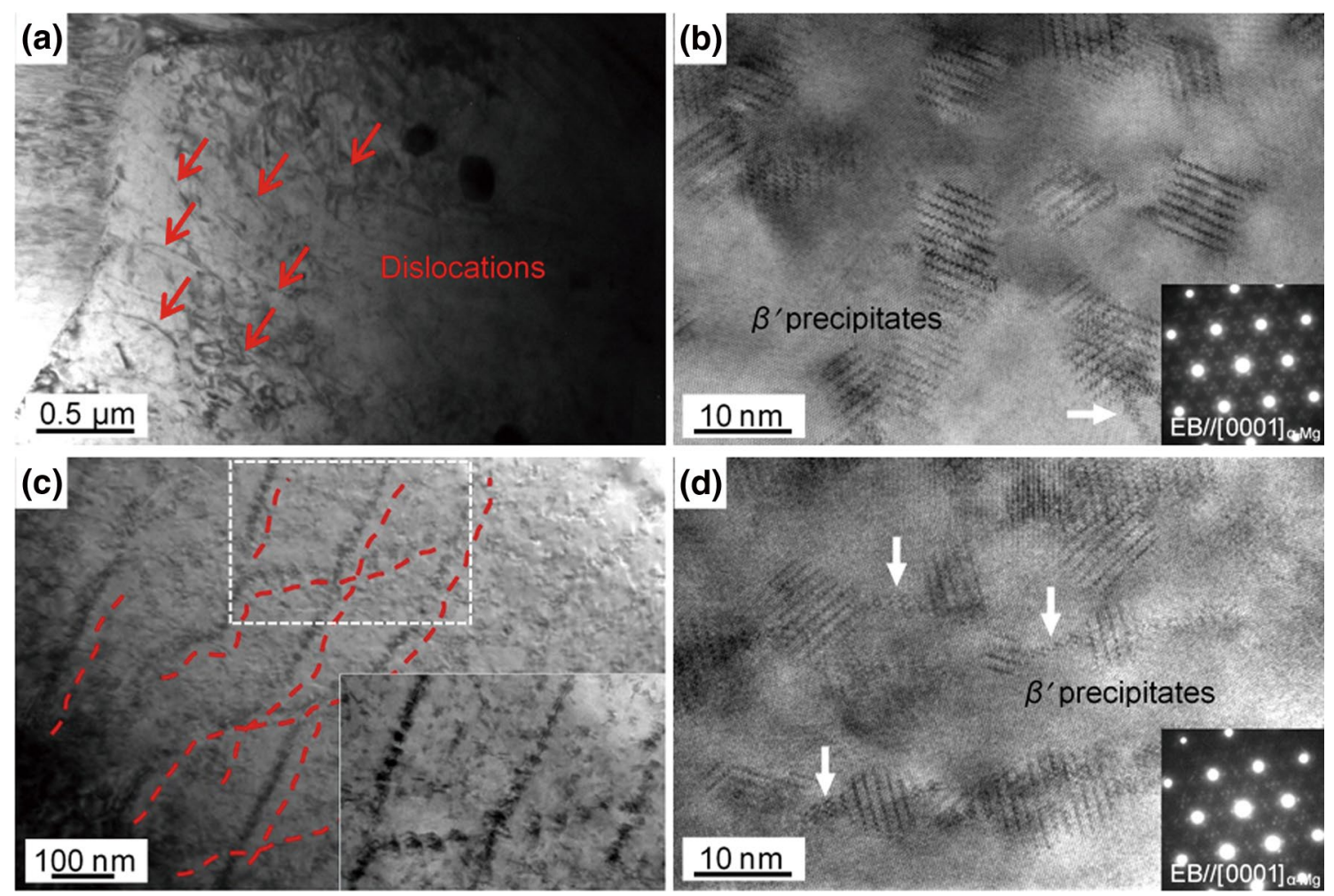

Fig. 3 TEM observations of the a EPD, $\mathbf{b}$ E + TSA , $\mathbf{c}, \mathbf{d}$ EPD + TSA samples: b-d TEM images and corresponding SAED patterns taken from the precipitates inside DRXed grains along $[0001]_{\alpha-M g}$

precipitates formed during hot extrusion and its precipitation behavior was mainly affected by the extrusion process [25]. Figure $4 \mathrm{c}$ shows the mapping result obtained from the boxed region in Fig. 4b, indicating the enrichment of Gd, Er and $\mathrm{Zn}$ atoms in the precipitates, while $\mathrm{Zn}$ mainly presented in the basal precipitates. The $\gamma^{\prime}$ precipitates with the segregation of heavy RE and $\mathrm{Zn}$ elements and the closed micro-space structure generated by the $\beta^{\prime}$ and $\gamma^{\prime}$ precipitates could prevent the propagation and growth of microcracks [26]. This might be responsible for the high ductility of the samples (Fig. 1b). Therefore, the bimodal structure, small $\beta-\mathrm{Mg}_{5} \mathrm{RE}$ phase and dense $\gamma^{\prime}$ precipitates obtained via extrusion ensured the good ductility of the present alloy.

\section{Conclusion}

In the present study, a Mg-12Gd-1Er-1Zn-0.9Zr (wt\%) alloy with ultra-high strength and good ductility was successfully developed via extrusion, pre-deformation and two-stage aging. The alloy exhibited excellent strength-ductility balance, with YS of $506 \mathrm{MPa}$, UTS of $549 \mathrm{MPa}$ and EL of $8.2 \%$. Pre-deformation had little effect on the microstructure and macro-texture, but served primarily to introduce lots of dislocations, resulting in strain hardening and providing more nucleation sites together with the subsequent two-stage aging treatment. The finer and denser $\beta^{\prime}$ precipitates mainly contributed to the enhanced strength, and the bimodal structure, small $\beta-\mathrm{Mg}_{5} \mathrm{RE}$ phase and dense $\gamma^{\prime}$ precipitates obtained via extrusion ensured the good ductility of the alloy. The current study provides an effective way to develop high-performance $\mathrm{Mg}$ alloys.

Acknowledgements This work was supported by the National Key Research and Development Program of China (Nos. 2016YFB0301101 and 2016YFB0301000), the Key Science and Technology Program of Beijing Municipal Commission of Education (No. KZ201810005005), the National Natural Science Fund of China (No. 51801004) and the Beijing Natural Science Foundation (No. 2192006). 

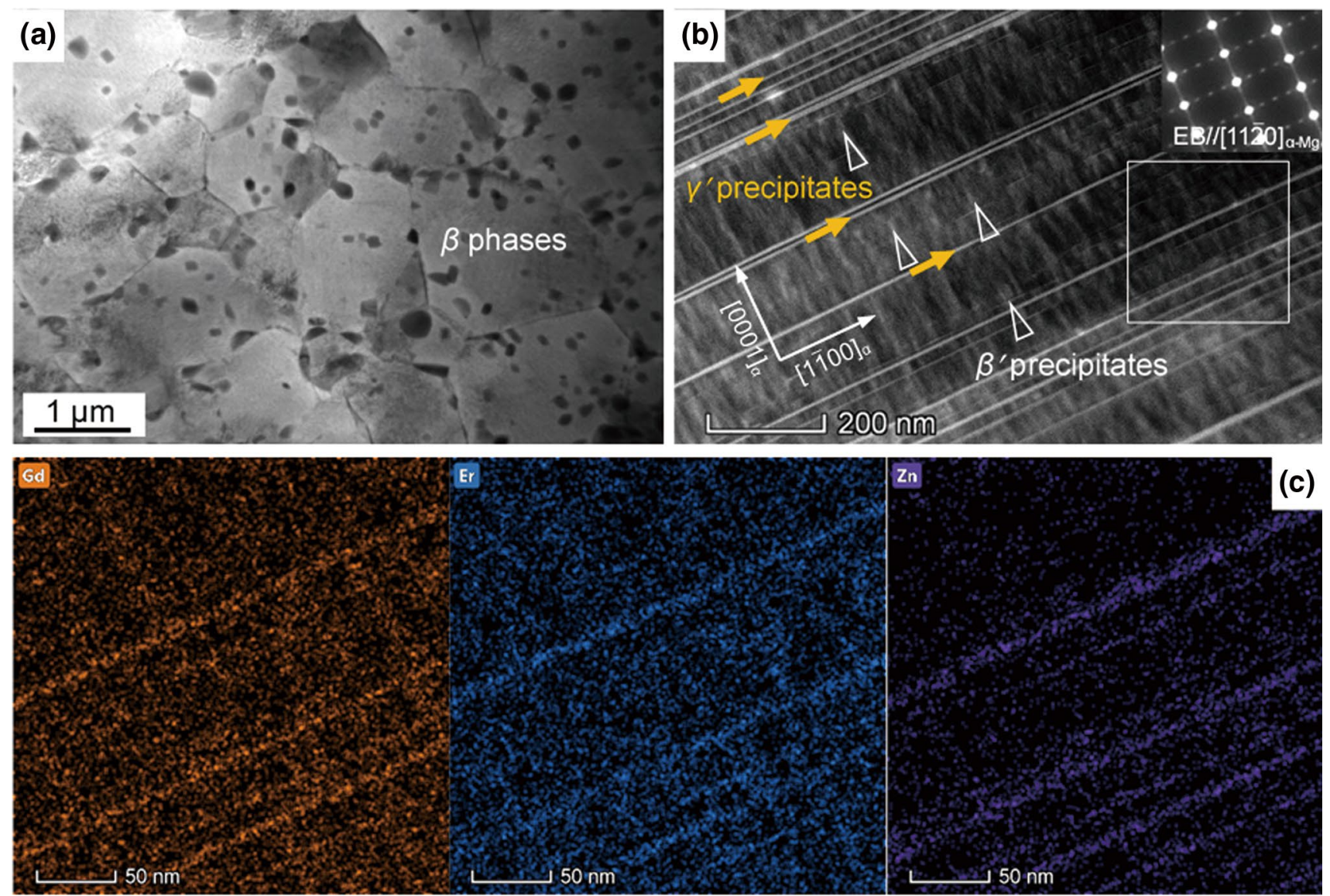

Fig. 4 TEM observations of the EPD + TSA sample: a BF image of the dynamic precipitates, b HAADF-STEM micrograph and corresponding SAED pattern taken from the precipitates inside worked grains along $11 \overline{2} 0]_{\alpha-M g}$, $\mathbf{c}$ mapping of Gd, Er and Zn elements in the boxed region in $\mathbf{b}$

\section{References}

[1] B.S. Li, K. Guan, Q. Yang, X.D. Niu, D.D. Zhang, Z.J. Yu, X.H. Zhang, Z.M. Tang, J. Meng, J. Alloys. Compd. 763, 120 (2018)

[2] P.F. Qin, Q. Yang, K. Guan, F.Z. Meng, S.H. Lv, B.S. Li, D.D. Zhang, N. Wang, J.H. Zhang, J. Meng, Mater. Sci. Eng. A 764, 138254 (2019)

[3] W. Rong, Y. Zhang, Y.J. Wu, J. Chen, Y.L. Chen, M. Sun, L.M. Peng, Mater. Sci. Eng. A 740, 262 (2019)

[4] T. Homma, N. Kunito, S. Kamado, Scr. Mater. 61, 644 (2009)

[5] X.B. Zheng, W.B. Du, Z.H. Wang, S.B. Li, K. Liu, X. Du, Mater. Lett. 212, 155 (2018)

[6] Z.J. Yu, Y.D. Huang, X. Qiu, G.F. Wang, F.Z. Meng, N. Hort, J. Meng, Mater. Sci. Eng. A 622, 121 (2015)

[7] J.F. Nie, Metall. Mater. Trans. A 43, 3891 (2012)

[8] J.H. Zhang, S.J. Liu, R.Z. Wu, L.G. Hou, M.L. Zhang, J. Magnes. Alloy. 6, 277 (2018)

[9] J.M. Rosalie, H. Somekawa, A. Singh, T. Mukai, Mater. Sci. Eng. A 539, 230 (2012)

[10] R.G. Li, J.F. Nie, G.J. Huang, Y.C. Xin, Q. Liu, Scr. Mater. 64, $950(2011)$

[11] A.F. Crawley, B. Lagowski, Metall. Trans. 5, 949 (1974)

[12] K. Oh-ishi, K. Hono, K.S. Shin, Mater. Sci. Eng. A 496, 425 (2008)

[13] X.M. Zhang, C.P. Tang, Y.L. Deng, L. Yang, Mater. Des. 32, 4994 (2011)
[14] G.L. Shi, D.F. Zhang, H.J. Zhang, X.B. Zhao, F.G. Qi, K. Zhang, Trans. Nonferrous Met. Soc. China 23, 586 (2013)

[15] X.W. Heng, Y. Zhang, W. Rong, Y.J. Wu, L.M. Peng, Mater. Des. 169, 107666 (2019)

[16] B. Li, B.G. Teng, D.G. Luo, Acta Metall. Sin. Engl. Lett. 31, 1009 (2018)

[17] M.G. Jiang, C. Xu, T. Nakata, H. Yan, R.S. Chen, S. Kamado, J. Alloy. Compd. 694, 1214 (2017)

[18] C. Xu, T. Nakata, X.G. Qiao, M.Y. Zheng, K. Wu, S. Kamado, Sci. Rep. 7, 40846 (2017)

[19] D.F. Zhang, G.L. Shi, X.B. Zhao, F.G. Qi, Trans. Nonferrous Met. Soc. China 21, 15 (2011)

[20] T. Honma, T. Ohkubo, K. Hono, S. Kamado, Mater. Sci. Eng. A 395, $301(2005)$

[21] K. Wen, K. Liu, Z.H. Wang, S.B. Li, W.B. Du, J. Magnes. Alloy. 3, $23(2015)$

[22] J.X. Zheng, Z. Li, L.D. Tan, X.S. Xu, R.C. Luo, B. Chen, Mater. Charact. 117, 76 (2016)

[23] F.B. Klose, A. Ziegenbein, J. Weidenmüller, H. Neuhäuser, P. Hähner, Comput. Mater. Sci. 26, 80 (2003)

[24] X.X. Wei, L. Jin, F.H. Wang, J. Li, N. Ye, Z.Y. Zhang, J. Dong, J. Mater. Sci. Technol. 44, 19 (2020)

[25] C. Xu, G.H. Fan, T. Nakata, X. Liang, Y.Q. Chi, X.G. Qiao, G.J. Cao, T.T. Zhang, M. Huang, K.S. Miao, M.Y. Zheng, S. Kamado, H.L. Xie, Metall. Mater. Trans. A 49, 1931 (2018)

[26] J.F. Wang, K. Wang, F. Hou, S.J. Liu, X. Peng, J.X. Wang, F.S. Pan, Mater. Sci. Eng. A 728, 10 (2018) 